\title{
Verification of static strain and deformation of industrial robot actuator in ANSYS environment
}

\author{
Marek Kočiško ${ }^{1,}$, Lukáš Blaško ${ }^{1}$, Petr Baron ${ }^{1}$ and Dušan Paulišin ${ }^{2}$ \\ ${ }^{1}$ Faculty of Manufacturing Technologies, Technical University of Košice, Štúrova 31, 08001 Prešov, \\ Slovakia \\ ${ }^{2}$ SPINEA Technologies s.r.o., Volgogradská 13, 08001 Prešov, Slovakia
}

\begin{abstract}
The article describes the process of experimental analyses in verifying the static strain and deformation of industrial robot actuator. The experiments were carried out in ANSYS analytical system environment. The actuator body behaviour has been verified with respect to its required high accuracy when subjected to radial, axial and torque loads. Due to load, high pressures and consequent partial or total deformation of body, which may result in a deviation in hundreds of millimetres. In case of unsatisfactory results, it is necessary to modify body actuator from structural point of view, either by adding a layer of material to weakened surfaces or by changing the holes layout and functional holes of the actuator. The results were compared with prescribed values of slope of selected material. In first phase of the experiment, forces were applied individually to the body, next one being experimented with their concurrent action.
\end{abstract}

\section{Introduction}

Based on the request of partner company Spinea Technologies s.r.o. Prešov which provides the construction of various types of products and technical systems especially in the field of mechatronics and electrical drives, experimental analyses aimed at the static analyses of pressure and deformation in the environment of ANSYS system have been performed at our workplace. The Company Spinea Technologies s.r.o. Prešov provides the development and production of highly precise actuators of the DriveSpin type characterized by outstanding mechanical properties and the use of a compact design AC servo motor. As the only one of its kind in the world, DriveSpin actuators can meet the highest demands of customers in terms of stiffness, transmission precision, transmission of large torques, roll and torsion stiffness, precision and lightness.

The required input parameters for the realization of analysis were provided by the Company Spinea Technologies s.r.o. The analyses focused on an actuator of the 070 series in DSM modification having the special structure of a body which allows for the versatile connection of the whole actuator by means of screws attached to the bottom or the back part when additional equipment is not necessary to attach it.

\footnotetext{
*Corresponding author: marek.kocisko@tuke.sk
} 
The DSM 070 modular rotary positioning module provide controlled rotary motion and transfer of torque with a high positioning accuracy and precision. The output flange of the module allows capturing both radial and axial forces. Rated output torque is $50 \mathrm{Nm}$ and acceleration/braking output torque is $100 \mathrm{Nm}$ (Table 1). The DSM 070 feature a special design, which allows versatile connections, also without additional devices. Actuators can be combined in many ways using the modular system. The simple design integration ability and small dimensions allow creating kinematic assemblies from DSM modules for end effectors, but also for additional devices and positioners. The selection of a module size depends on the required load carrying capacity and the number of degrees of freedom of the motion axis. The DSM Series is characterized by simple and quick assembly and reduces overall cost. Compact design ensures optimum mounting options and application possibilities, even in confined installation spaces. This actuator is used in applications with request of high torque density, precision and dynamics.

Table 1. The modular actuator DSM is characterized by these technical parameters

\begin{tabular}{|l|c|c|c|}
\hline DS Actuator & & & DSM 070 \\
\hline Reduction ratio & $\mathrm{I}$ & & 57,75 \\
\hline Rated output torque & $\mathrm{T}_{\mathrm{r}}$ & $\mathrm{Nm}$ & 50 \\
\hline Acceleration/braking output torque & $\mathrm{T}_{\max }$ & $\mathrm{Nm}$ & 100 \\
\hline Rated input speed of the reduction gear & $\mathrm{n}_{\mathrm{r}}$ & $\mathrm{min}^{-1}$ & 2000 \\
\hline Maximum allowed input speed of the reduction gear & $\mathrm{n}_{\max }$ & $\mathrm{min}^{-1}$ & 5000 \\
\hline Tilting stiffness & $\mathrm{M}_{\mathrm{t}}$ & $\mathrm{Nm} / \operatorname{arcmin}$ & 35 \\
\hline Torsional stiffness & $\mathrm{k}_{\mathrm{t}}$ & $\mathrm{Nm} / \operatorname{arcmin}$ & 7 \\
\hline Maximum lost motion & $\mathrm{LM}$ & $\operatorname{arcmin}$ & $<1.5$ \\
\hline Hysteresis & $\mathrm{H}$ & $\mathrm{arcmin}$ & $<1.5$ \\
\hline Maximum tilting moment & $\mathrm{M}_{\mathrm{c}}$ & $\mathrm{Nm}$ & 142 \\
\hline Rated radial force & $\mathrm{F}_{\mathrm{rR}}$ & $\mathrm{kN}$ & 2.8 \\
\hline Maximum axial force & $\mathrm{F}_{\mathrm{a} \text { max }}$ & $\mathrm{kN}$ & 4.1 \\
\hline Allowed temperature range & & ${ }^{\circ} \mathrm{C}$ & $-10{ }^{\circ} \mathrm{C}$ to $+40{ }^{\circ} \mathrm{C}$ \\
\hline Reduction gear maximum allowed temperature & & ${ }^{\circ} \mathrm{C}$ & $65^{\circ} \mathrm{C}$ \\
\hline
\end{tabular}
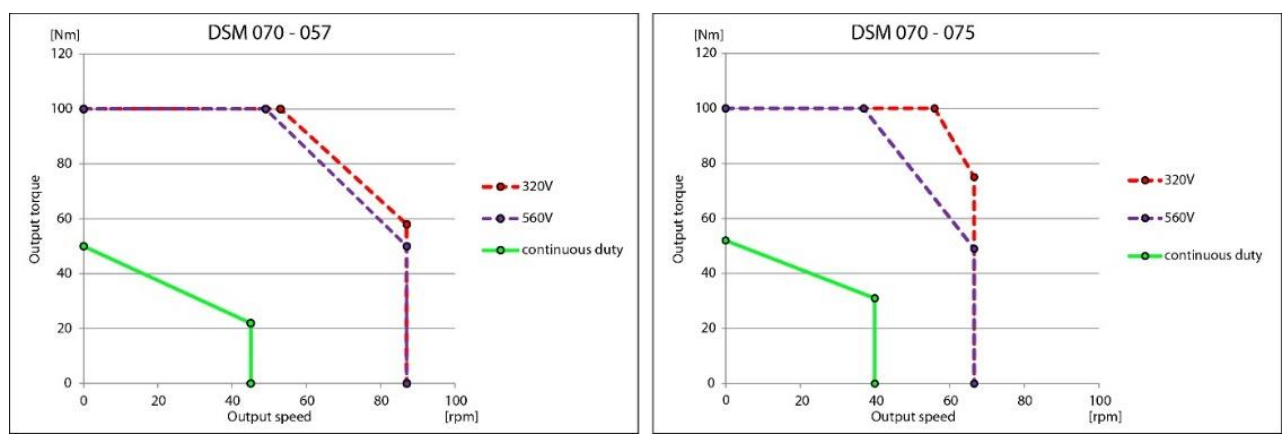

Fig. 1. Performance Characteristics. 


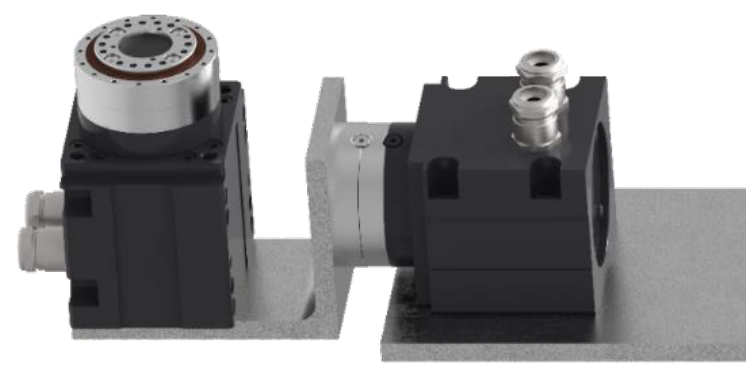

Fig. 2. Example of use (connection).

In the following equations, $+\mathrm{i}_{\text {out }}$ represents input and output rotations in one direction, $-\mathrm{i}_{\text {out }}$ represents input and output rotations in the opposite direction.

$$
i_{\text {out }}=\frac{\text { speed }_{\text {input }}}{\text { speed }_{\text {output }}}
$$
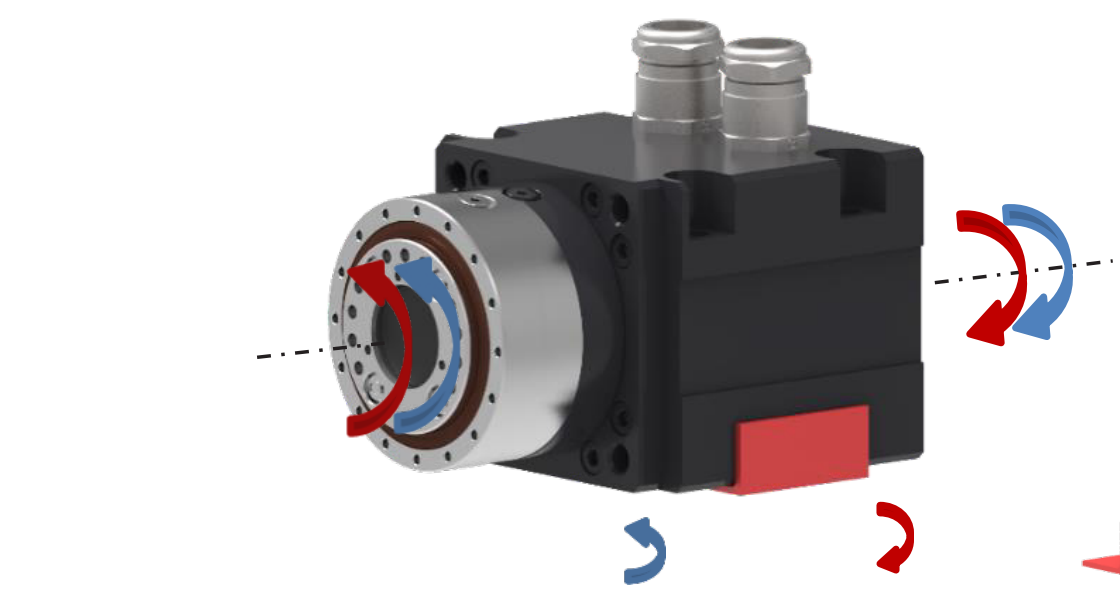

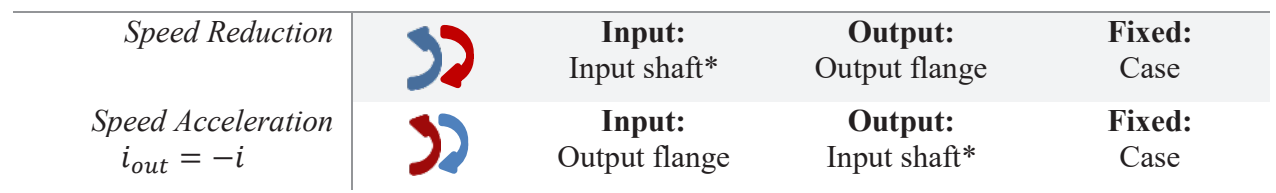

*Shaft inside the actuator (integrated drive)

Fig. 3. Rotation direction and reduction ratio.

The analyses focused on external stress - radial force, axial force and torque. The suitability of the body with respect to its high positioning precision was checked by this experiment. Under stress, high pressure may arise and subsequently the whole or a part of the body may be deformed, which would cause a deviation in hundredths of millimetres. In the event of unsatisfactory results, it is necessary to make structural repairs either by adding a layer of material to the weakened surface or modifying the layout of holes and the holes of the actuator, which would ensure that stress is exerted on the thin surface. The results were compared with the yield strength of the selected material. In the first stage of the experiment, individual forces are applied to the body. In the second stage, the forces are applied simultaneously. By applying all the forces, significant deformation or total deformation along with deviation may occur and be caused by exerting pressure and exceeding the yield strength. 


\section{The analysis of observed stresses and distortions of DSM 70 actuator body}

The analysis of stresses and deformation of the observed actuator body was realized in the environment of ANSYS analytical system. In particular, what was performed is the analysis of maximum stress (von Mises) which is based on the von Mises-Hencky theory known as a shear stress theory or a maximum drawing theory. A safety factor was calculated based on the calculated maximum load bearing capacity and permitted load bearing capacity of the material $[2,5,6]$.

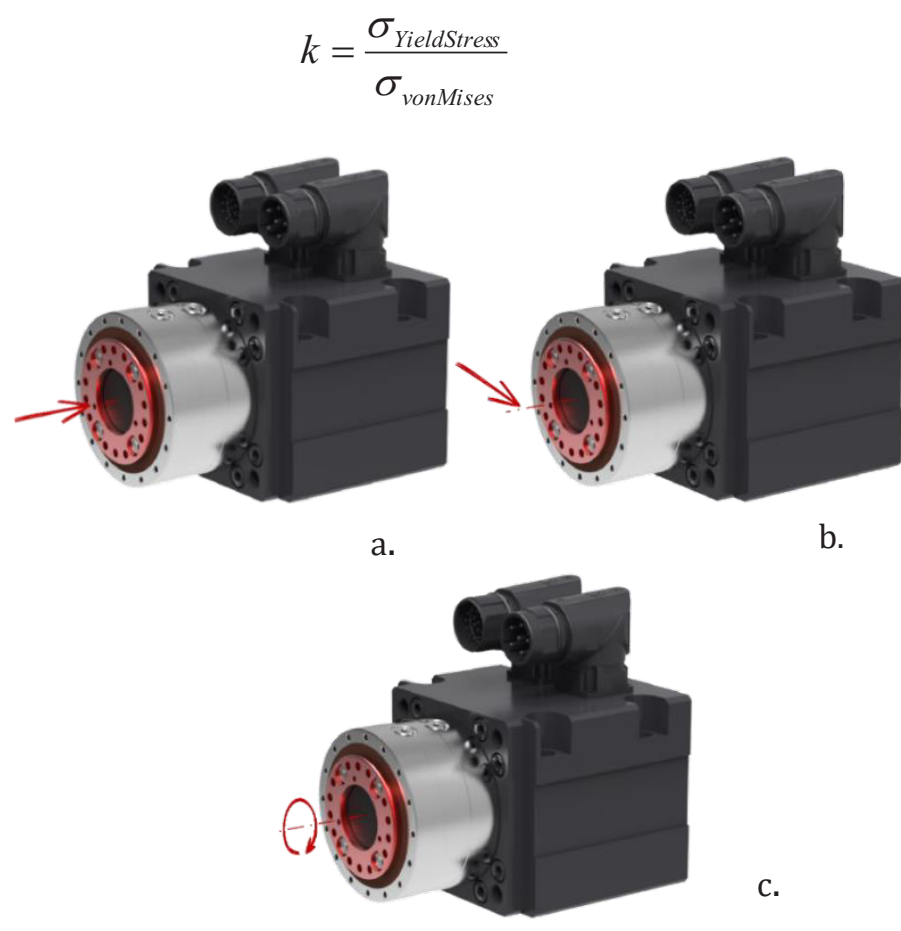

Fig. 4. Effect of axial force (a.) radial force (b.) and torque (c.) on actuator gearbox DSM 070.

The analysis of deformation was performed based on the simulation of total deformation where a resulting maximum value in $\mathrm{mm}$ had to be lower than the value of $20 \mu \mathrm{m}(0.02$ $\mathrm{mm}$ ) which was required by the Company Spinea Technologies s.r.o. with respect to the deployment of the DSM module in the manufacturing CNC machines and equipment. The analysis was performed using different means of attaching the body and applying various external forces to the body. Three forces were applied to the body, namely axial force amounting to $\mathrm{F}=3.7 \mathrm{kN}$ applied to the front part of body, radial force $\mathrm{F}=2.6 \mathrm{kN}$ and torque $\mathrm{Ml}=100 \mathrm{Nm}$ (Fig. 4). The given values of forces were simulated using the different means of attaching the body. The first type of analysis assumed the attachment of a back part of body. Subsequently, the body was attached on its bottom (Fig. 5).

Regarding the minimum thickness of walls of the body, which was designed to the value of $4.5 \mathrm{~mm}$, what was chosen is a hollow aluminium alloy profile EN AW-6082 [Al Si1MgMn] with T6 heat treatment whose minimum yield strength Rp0,2 is equal to $250 \mathrm{MPa}$. This value was a starting parameter for comparing the results of the analysis. With respect to its chemical and physical characteristics and advantages over other materials (like steel), an extruded profile made of the above mentioned material was used to analyse stress and deformation of the body of the actuator. It is light, firm, noncorrosive, it 
may be processed to gain better characteristics and it is used in several industrial fields. At the same time, it is relatively stable, formable and forgeable and it has good tensile strength and good electrical and thermal conductivity $[3,4]$.

\subsection{The stress of the body at a value of $100 \mathrm{Nm}$ of torque (attachment on the back of the body)}

The body is stressed with torque and it is attached at its back part. The value of stress is shown in Fig. 5 (a). The maximum stress has a value of 9.4991MPa.

The value of permitted stress for the material according to EN AW 6082 is $250 \mathrm{MPa}$. The factor of safety has a value of 26 . The comparison of observed and permitted stress $(9.4991 \mathrm{MPa} \leq$ $250 \mathrm{MPa}$ ) confirms that the proposed material is convenient at the maximum torque of $100 \mathrm{Nm}$.

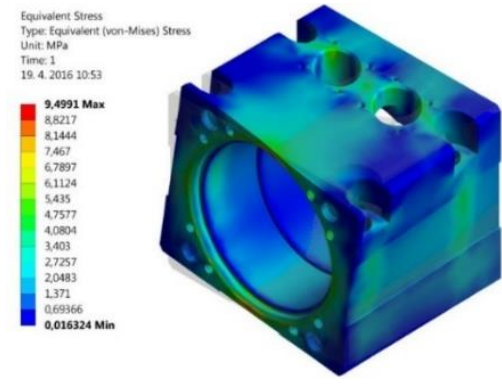

a.

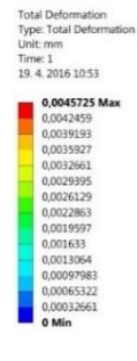

b.

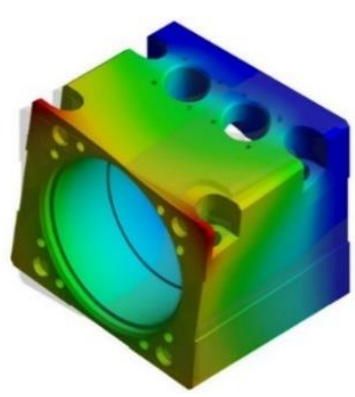

Fig. 5. Resulting stress (a.) and deformation (b.) of the actuator body under load exerted by torque (attachment on the back part).

The value of deformation under stress by torque applied to the body (the attachment on the back part) is shown in Fig. 5 (b.). The maximum deformation is $0.0045 \mathrm{~mm}$. Based on the assumed use of module in the manufacturing of $\mathrm{CNC}$ machines and equipment; we can conclude that the value of deformation is convenient.

\subsection{The stress of the body at a value of $100 \mathrm{Nm}$ of torque (the attachment on the back of the body)}
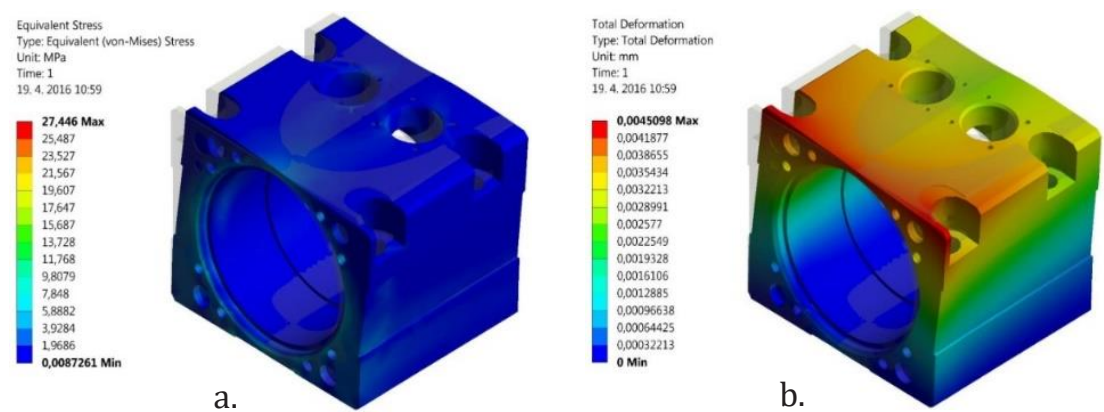

Fig. 6. Resulting stress (a.) and deformation (b.) of the actuator body under load exerted by torque (attachment on the bottom part).

In this case, the value of stress is displayed in Fig. 6 (a). The maximum stress has a value of $27.446 \mathrm{MPa}$. In accordance with EN AW 6082, the value of permitted stress for the material is $250 \mathrm{MPa}$. The safety factor has a value of 9 . The comparison of identified and permitted stress $(27.446 \mathrm{MPa} \leq 250 \mathrm{MPa})$ confirms that the proposed material is convenient at the 
maximum torque of $100 \mathrm{Nm}$. The value of deformation under load exerted by torque to the body (the attachment on the back part) is shown in Fig. 6 (b.) where the maximum deformation amounts to $0.0045 \mathrm{~mm}$. Based on the assumed use of the module in the manufacturing of $\mathrm{CNC}$ machines and equipment, the value of deformation is convenient.

\subsection{The stress of the body at a value of $3.7 \mathrm{kN}$ of axial force (the attachment on the back of the body)}

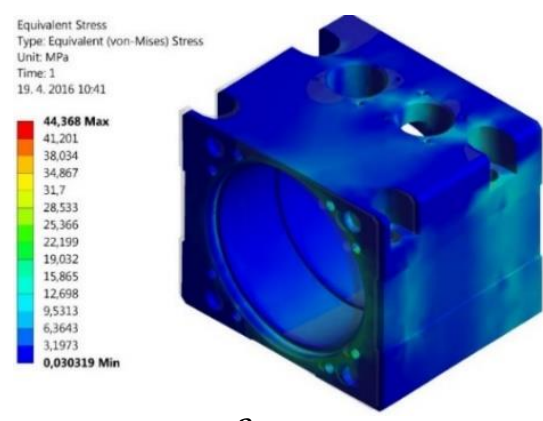

a.

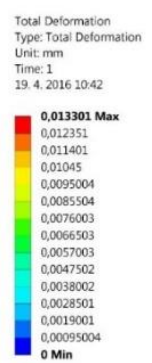

b.

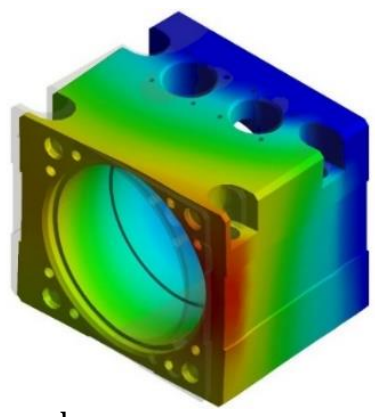

Fig. 7. Resulting stress (a.) and deformation (b.) of the actuator body under load exerted by axial force (attachment on the back part).

The axial force was applied to the body with the attachment at the back (Fig. 7). The value of stress is shown in Fig. 7 (a.). The maximum stress has a value of $44.368 \mathrm{MPa}$. The value of permitted stress for the material according to EN AW 6082 is $250 \mathrm{MPa}$. The factor of safety has a value of 5 . The comparison of observed and permitted stress $(44.368 \mathrm{MPa} \leq 250 \mathrm{MPa})$ confirms that the proposed material is convenient at the maximum axial force of $3.7 \mathrm{kN}$.

The value of deformation under load exerted by axial force to the body (the attachment on the back part) is shown in Fig. 7 (b.). The maximum deformation is $0.0133 \mathrm{~mm}$. If the assumed module is put into the manufacturing of $\mathrm{CNC}$ machines and equipment, the value of deformation is convenient.

\subsection{The stress of the body at a value of $3.7 \mathrm{kN}$ of axial force (attachment on the bottom of the body)}

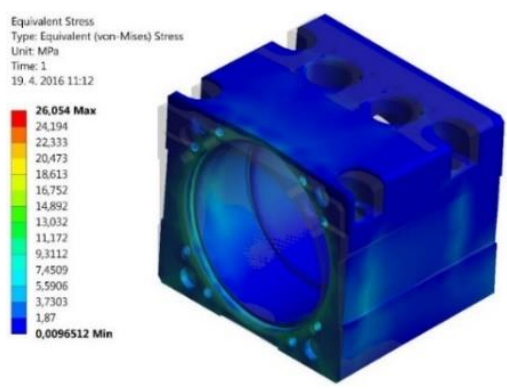

a.

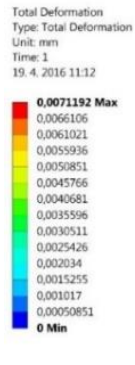

b.

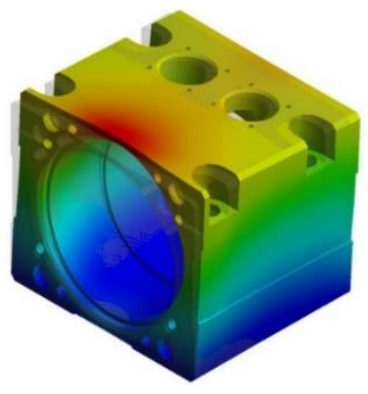

Fig. 8. Resulting stress (a.) and deformation (b.) of the actuator body under load exerted by axial force (attachment on the bottom part).

When axial force was applied to the body with the attachment on the bottom, the value of stress amounted to 26.054MPa. In accordance with EN AW 6082, the value of permitted 
stress for the material is $250 \mathrm{MPa}$. The safety factor has a value of 9 . The comparison of observed and permitted stress $(26.054 \mathrm{MPa} \leq 250 \mathrm{MPa})$ confirms that the proposed material is convenient at the maximum axial force of $3.7 \mathrm{kN}$.

The value of deformation under load exerted by axial force to the body (attachment on the bottom) is shown in Fig. 8 (b.) and it amounted to $0.0071 \mathrm{~mm}$. If the assumed module is put into the manufacturing of $\mathrm{CNC}$ machines and equipment, the value of deformation is convenient.

\subsection{The stress of the body at a value of $2.6 \mathrm{kN}$ of radial force (attachment on the back of the body)}

The body of the actuator was subjected to radial force. The body was attached on its back part. The value of stress is shown in Fig. 9 (a.) and maximum stress amounted to $27.175 \mathrm{MPa}$. In accordance with EN AW 6082, the value of permitted stress for the material amounts to $250 \mathrm{MPa}$. The safety factor has a value of 9 . The comparison of identified and permitted stress $(27.175 \mathrm{MPa} \leq 250 \mathrm{MPa})$ confirms that the proposed material is convenient at the maximum radial force of $2.6 \mathrm{kN}$.

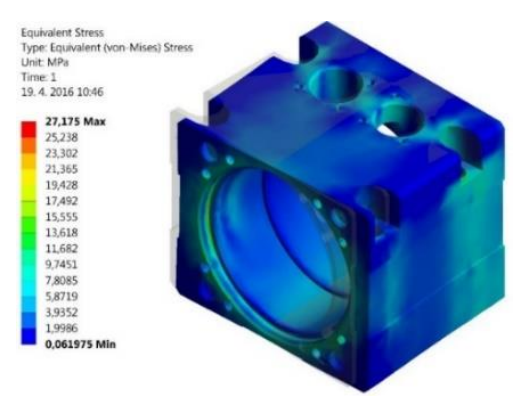

a.

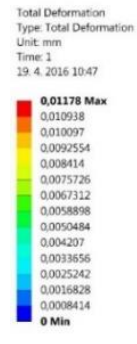

b.

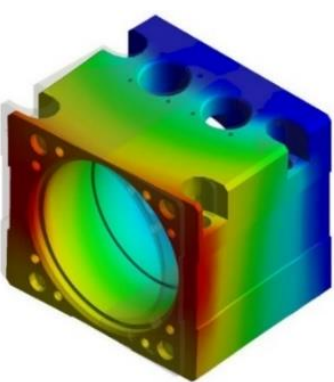

Fig. 9. Resulting stress (a.) and deformation (b.) under load exerted by radial force (attachment on the back part).

The value of deformation under load exerted by radial force to the body (attachment on the back) is shown in Fig. 9 (b.) and maximum deformation amounted to $0.0117 \mathrm{~mm}$. If the assumed module is put into the manufacturing of $\mathrm{CNC}$ machines and equipment, the value of deformation is convenient.

\subsection{The stress of the body at a value of $2.6 \mathrm{kN}$ of radial force (attachment on the bottom of the body)}

When radial force was applied to the body and the body was attached on its back, the maximum value of stress amounted to $71.503 \mathrm{MPa}$. In accordance with EN AW 6082, the value of permitted stress for the material amounts to $250 \mathrm{MPa}$. The safety factor has a value of 3 . The comparison of identified and permitted stress $(71.503 \mathrm{MPa} \leq 250 \mathrm{MPa})$ confirms that the proposed material is convenient at the maximum radial force of $2.6 \mathrm{kN}$.

The value of deformation under load exerted by radial force to the body (attachment on the bottom) is shown in Fig. 10 (b.) and maximum deformation amounted to $0.0079 \mathrm{~mm}$. If the assumed module is put into the manufacturing of $\mathrm{CNC}$ machines and equipment, the value of deformation is convenient. 


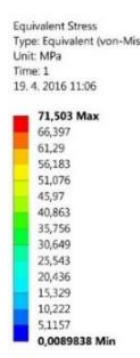

a.

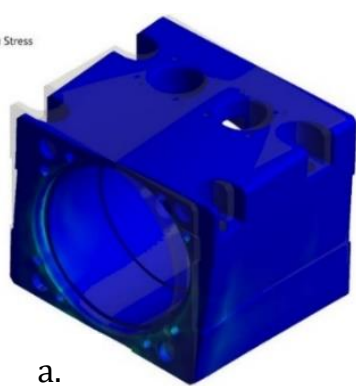

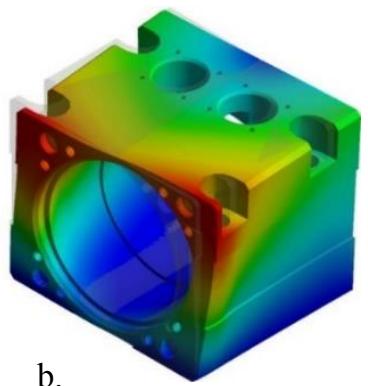

b.

Fig. 10. Resulting stress (a.) and deformation (b.) under load exerted by radial force to the body (attachment on the bottom).

\section{Conclusion}

The task of the experiment conducted was to predict the behaviour of the body of the actuator under load simultaneously exerted by radial and axial forces along with torque with respect to the selected material of aluminium alloy. During the experiment, the conditions and state were being checked by the analysis in the environment of ANSYS analytical system. The results of experiments demonstrated the structural suitability of the selected material of aluminium alloy [Al SilMgMn] with obligatory heat treatment in accordance with EN AW-6082. The results were compared with the values of yield strength for the selected material. During potential experiments in future, it would be the best to perform simulation analyses under dynamic load, where more realistic conditions would be created with respect to stress exerted to the body as in practice.

The Ministry of Education, Science, Research and Sport of SR supported this work, contract VEGA No. 1/0492/16, and ITMS project 26220220125.

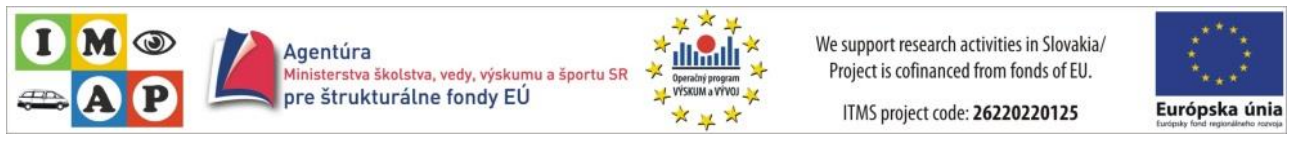

\section{References}

1. M. Staniszewski, S. Legutko, P. Raos, Tehnicki vjesnik-technical gazette, 21,11771181, ISSN 1330-3651 (2014)

2. S. Olejarova, J. Dobransky, J. Svetlik, M. Pituk, Measurement, 106, 18-25, ISSN: 0263-2241 (2017)

3. P. Monka, K. Monkova, M. Balara, S. Hloch, J. Rehor, A. Andrej, M. Somsak, Int J of Adv Man Tech, 85, 2325-2343, ISSN: 0268-3768 (2016)

4. J. Macala, I. Pandova, A. Panda, Gospodarka surowcami mineralnymi-Mineral Resources Management, 1, 33, 125-137, ISSN: 0860-0953 (2017)

5. Š. Salokyová, R. Krehel, Acta Technica CSAV, 1, 61, 45-57, ISSN: 0001-7043 (2016)

6. K. Brezikova, M. Hatala, J. Duplak, D. Mital', S. Radchenko, F. Botko, MM Science J., 1082-1085, ISSN: 18031269 (2016) 